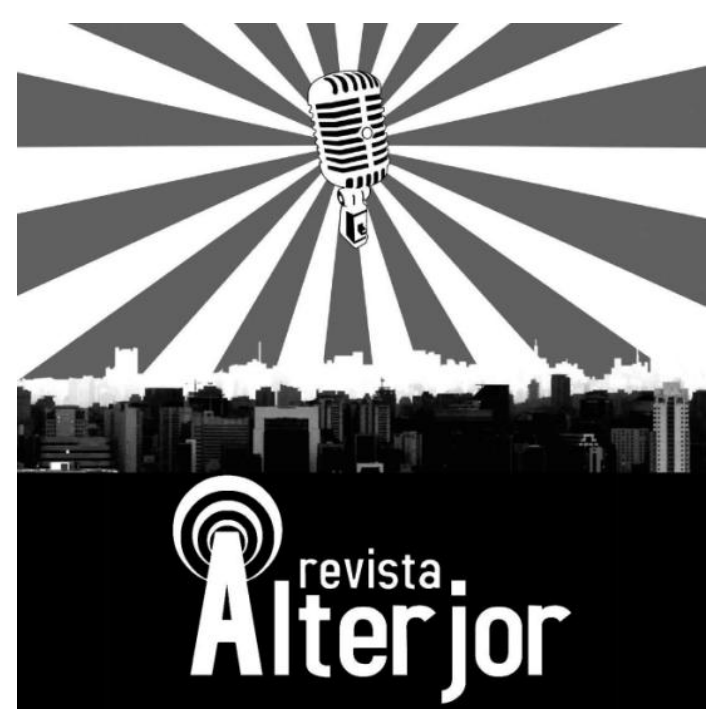

ESPACO ALTERNATIVO

\title{
CONSEQUENCIAS DAS DERRUBADAS E QUEIMADAS DE VEGETAÇÃO: PRÁTICAS UTILIZADAS PELOS AGRICULTORES DA TRANSASSURUNI ALTAMIRA PARÁ 2021
}

Maria José Pereira de Souza Flor ${ }^{1}$

RESUMO: O objetivo deste artigo é verificar e analisar através de pesquisa as perdas de nutrientes, gerado pelas queimadas no Assentamento Bom Jardim I, a dinâmica realizada na região de Altamira PA. Como são utilizadas as derrubadas e as queimadas nos lotes? Quais as consequenciais das queimadas para a população? Como o Sistema de Saúde trabalha com essas questões diante do Período da Pandemia. Segundo os profissionais da Saúde os aumentos de doenças respiratórias aumentam nesse no período das queimadas, nesse contexto os mais afetados são os idosos e as crianças. Porém outros problemas que as queimadas provocam na natureza como perda de nitrogênio, fosforo, potássio e micronutrientes. Através do resultado da pesquisa pretendemos mostrar para os assentados outras alternativas de produção sem queimadas e inserir a participação das comunidades que têm nas queimadas sua base técnica, uma vez que elas concentram informação crucial quanto à viabilidade de práticas alternativas e quanto aos ativos econômicos, sociais e ambientais em jogo.

PALAVRAS-CHAVE: solo. assentamento. microrganismo. minerais. nutrientes.

ABSTRACT: The objective of this article is to verify and analyze through research the loss of nutrients, generated by the burnings in the Boom Jordi I settlement, the dynamics carried out in the region of Altamira PA. How are felling and burning used in the lots? What are the consequences of the fires for the population? How the Health System works with these issues in the face of the Pandemic Period? According to health professionals, increases in respiratory diseases increase during the period of fires, in this context the most affected are the elderly and children. But other problems that fires cause in nature such as loss of nitrogen, phosphorus, potassium and micronutrients. Through the research results, we intend to show the settlers other production alternatives without fires and to include the participation of communities that have their technical base in the fires, since they concentrate crucial information on the feasibility of alternative practices and on economic and social assets and environmental at play.

KEYWORDS: soil. settlement. microorganism. minerals. nutrients.

\footnotetext{
${ }^{1}$ Licenciatura plena em Pedagogia Faculdade Pan Americana (FPA, 2009) com especialização em Gestão Escolar pela Faculdade de Minas (Faminas, 2021). E-mail: mj1686985@gmail.com
}

\section{Revista ALTERJOR}

Grupo de Estudos Alterjor: Jornalismo Popular e Alternativo (ECA-USP)

Ano 12 - Volume 01 - Edição 25 - Janeiro-Junho de 2022

Av. Professor Lúcio Martins Rodrigues, 443, Cidade Universitária, São Paulo, CEP: 05508-020 


\section{INTRODUÇÃO:}

As derrubadas e queimadas são práticas ancestrais comuns entre agricultores e pecuaristas no município de Altamira PA, na Região Norte, essa dinâmica elimina nutrientes essenciais à planta e altera características do solo. Utilizada com o objetivo de limpar e preparar o solo para o plantio, a queimada ainda é uma prática comum entre agricultores e pecuarista, em virtude de ser mão de obra barata, envolvem menos recursos financeiros.

Nesse sentido ela é realizada por produtores, sem acompanhamento técnico, por acreditarem que a queimada aumentaria a fertilidade do solo, assim como para limpeza de pastos e eliminação de restos vegetais. As queimadas, na maioria das vezes, ocorrem em grandes áreas e sem um sistema de controle de fogo, em diversas épocas do ano. E, o principal, sem licença concedida pelo órgão responsável e sem técnica especiais, com isso percebe-se que as queimadas é um problema que vem causando grandes sequelas para os agricultores.

Diante desse cenário percebe-se que essa prática tradicional contribui para 0 enfraquecimento do solo e outros fatores como: problemas físicos, químicos e biológicos com isso surgem a necessidade de um estudo mais detalhado sobre esse tema que será abordado através de uma pesquisa realizada no Assentamento. À vista disso, foi aplicada uma pesquisa no Assentamento do Bom Jardim I no período de 8 meses, esse estudo teve como objetivo apresentar para os assentados a quantidade de nutrientes, Nitrogênio (N), Fósforo (P), Potássio (k), micronutrientes que o solo perde com as queimadas. A coleta das amostras foi realizada com equipamento e com auxílio dos moradores do assentamento com orientação do técnico e engenheiro agrônomo, o material foi coletado de sete lotes de diferentes locais e levado para o laboratório da CEPLAC, para ser submetidos à análise química do solo e o nível de perca dos nutrientes como: nitrogênio, fósforo, potássio e micronutrientes. A análise transigirá a descrição do solo e do subsolo que passaram pelo processo de transformações em virtude das queimadas. $\mathrm{O}$ aumento da acedesse, perca de valor nutricional, fertilização,

Revista ALTERJOR

Grupo de Estudos Alterjor: Jornalismo Popular e Alternativo (ECA-USP)

Ano 12 - Volume 01 - Edição 25 - Janeiro-Junho de 2022

Av. Professor Lúcio Martins Rodrigues, 443, Cidade Universitária, São Paulo, CEP: 05508-020 


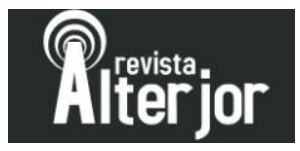

herança biológica, controle de pragas e doenças, nitrogênio e a matéria orgânica. Essa prática é considerada para o agricultor ainda a melhor metodologia na produção, no entanto é uma visão equivocada totalmente arcaica que contribuem para o empobrecimento do solo.

\section{METERIAL E MÉTODOS:}

Essa pesquisa foi realizada no Assentamento Bom Jardim I km 40, Rodovia Municipal PA Transassuruni, Altamira Pará, a pesquisa foi desenvolvida em duas etapas, $1^{\text {a }}$ etapa foi realizada a coleta de amostra do solo, no mês de maio de 2020, antes da derrubada da vegetação e queimada. Nas amostras do solo coletadas nas quatro profundidades, foram analisados os níveis de perdas de nutrientes, por 10-20 cm, 20-40 e 40-60 cm, transecto, 40 pontos distando $10 \mathrm{~m}$ entre eles, perfazendo no total $400 \mathrm{~m}$, em sete lotes do assentamento. O delineamento estatístico utilizado foi de blocos casualidades com parcelas subdivididas. A (posição da amostragem) em dois tratamentos, ou seja, área nativa (Bom Jardim I), e a $2^{\text {a }}$ coleta de amostra foram coletadas após a derrubada e queimada da vegetação no mês de dezembro, com as mesmas repetições, $10 \mathrm{~cm}, 10-20$ $\mathrm{cm}, 20-40 \mathrm{~cm}$ e 40-60 cm, em transecto, 40 pontos distando $10 \mathrm{~m}$ entre eles, perfazendo no total $400 \mathrm{~m}$. O delineamento estatístico utilizado foi de blocos casualidades com parcelas subdivididas. Nas amostras de solo coletadas nas quatro profundidades, foram analisadas as no laboratório da CEPLAC, para observar e analisar os níveis de perdas de nutrientes Nitrogénio (N), Fosforo (P), Potássio (K), micronutrientes, após a derruba da vegetação e queimada dos vegetais no solo. Diante desse contexto os dados da pesquisa analisada após as queimadas sofreram perdas de nutrientes como: Nitrogénio $(\mathrm{N})$, Fósforo $(\mathrm{P})$, Potássio $(\mathrm{K})$, micronutrientes cujas características foram estudadas através dos métodos de entrevistas com os moradores, irradiação e extração (Ferreira et al., 1999). Os dados da pesquisa foram organizados em duas tabelas, tabela com o resultado da $1^{\text {a }}$ coleta, antes da derruba da vegetação e queimada, nos 7 lotes do assentamento. A tabela número 2 representa as perdas de 


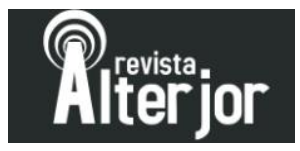

nutrientes após a queimada da vegetação. Nesse sentido as perdas de nutrientes são causadas pelas práticas de derrubada e queimada da vegetação. Prática utilizada pelos agricultores do assentamento. Na exposição do resultado da pesquisa, os assentados tiveram a oportunidade de observar que a metodologia usada por ambos causam problemas como: crimes ambientais contra a flora e a outra contra a fauna, provocando a baixa fertilidade e o empobrecimento do solo.

\section{1 - A dinâmica do desmatamento realizado na Região de Altamira}

O processo de desmatamento na região de Altamira, percebe-se que é bastante provecta, essa dinâmica vem perpetuando de geração para geração. Nesse sentido a dinâmica de desmatamento são classificadas em duas partes distintas, porém com o mesmo objetivo de produzir em pequena escala o agricultor retira da terra o sustento e o grande produtor com a produção intensiva e extensiva. Com essa visão de produção ancestral a baixa rentabilidade das atividades agrícolas, a inexistência de outras alternativas econômicas, o baixo padrão educacional, os fatores culturais arraigados no homem rural e a escassez de capital e de tecnologia, fazem com que o processo de derrubada e queimada seja predominante em toda Amazônia. O tamanho das propriedades também está implicitamente associado à perda de estabilidade das unidades produtivas. À medida que os lotes vão se fragmentando, fato corrente nas comunidades e nos povoados mais antigos, as famílias encontram dificuldades para se manter, face a baixa produtividade de suas propriedades e o pequeno espaço de tempo destinado ao pousio.

A movimentação do colono diante da dificuldade em se manter na terra fixa, possibilita a ele a procurar novas propriedades, em virtude da grande oferta de terras disponível faz com que seja relativamente fácil a aquisição de novas áreas mais distantes. (Homma et. al. 1991), mesmo para propriedades maiores, a venda da terra não constitui negócio especulativo que justifique grandes ganhos nos investimentos realizados. Com a divulgação dos lucros gerado pela produção da agropecuária surgem

\section{Revista ALTERJOR}

Grupo de Estudos Alterjor: Jornalismo Popular e Alternativo (ECA-USP)

Ano 12 - Volume 01 - Edição 25 - Janeiro-Junho de 2022

Av. Professor Lúcio Martins Rodrigues, 443, Cidade Universitária, São Paulo, CEP: 05508-020 


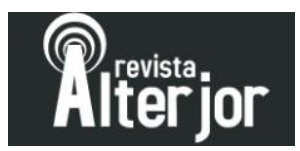

o fenômeno mais recente, como é o caso do interesse dos pequenos agricultores pela criação bovina, tem motivado a abertura de áreas destinadas a pastagens, após a derrubada de capoeira e seu cultivo com cultura anuais. Nesse contexto à expansão de criação bovina, nestas condições sempre é feito na forma de parceria, tais como a criação pelo sistema de meia ou a cessão de pasto em trocas de crias para superar a falta de capital inicial.

Diante dessa linha de produção é provável que essa dinâmica tenha desdobramento futuro quanto a sustentabilidade a longo prazo das pastagens, ao limite da área disponível, á necessidade de agregação de lotes e a queda de produção das culturas alimentares fica ao alto custo dos insumos modernos e a escassez de capital para promover atividades em escala apropriada, além da capacidade gerencial associada a preços que não compensam esses investimentos, terminaram provocando o colapso desse tipo de trabalho agrícola isso possibilita a entrada na área de outros segmentos de produtos interessados ou na criação da pecuária ou nos cultivos perenes, como exemplo; pimenta-do-reino, maracujá, laranja. Com o avanço das atividades de pecuária nas propriedades dos pequenos produtores rurais constata-se o aumento de derrubadas e queimadas.

Segundo (CARMENTA et al., 2013) as queimadas vêm aumentando nesses últimos dez anos, essa ascendência é em virtude da origem de uma trajetória de sustentação nitidamente provecta que prioriza essa dinâmica tanto para o pequeno quanto para o grande produtor. Nesse contexto o que se percebesse é uma teia que envolvem uma conjuntura com interesses particulares que sustentam essa estrutura, com dinâmicas ancestrais. Nesse sentido dados estatísticos comprovam que o pequeno utiliza essa prática em virtude de falta de conhecimento, porém o agronegócio visa o aumento na produção de fato, a dissociação entre desmatamento e fogo está sendo cada vez mais atestada por estudos de sensoriamento remoto não apenas ao longo do tempo, mas também do espaço (BARLOW et al., 2012; ARAGÃO; SHIMABUKURO, 2010; VASCONCELOS et). Com o aumento das atividades relacionada a pecuária entre o pequeno produtor rural, permanecem desenvolvendo praticas Vectra.

\section{Revista ALTERJOR}

Grupo de Estudos Alterjor: Jornalismo Popular e Alternativo (ECA-USP)

Ano 12 - Volume 01 - Edição 25 - Janeiro-Junho de 2022

Av. Professor Lúcio Martins Rodrigues, 443, Cidade Universitária, São Paulo, CEP: 05508-020 


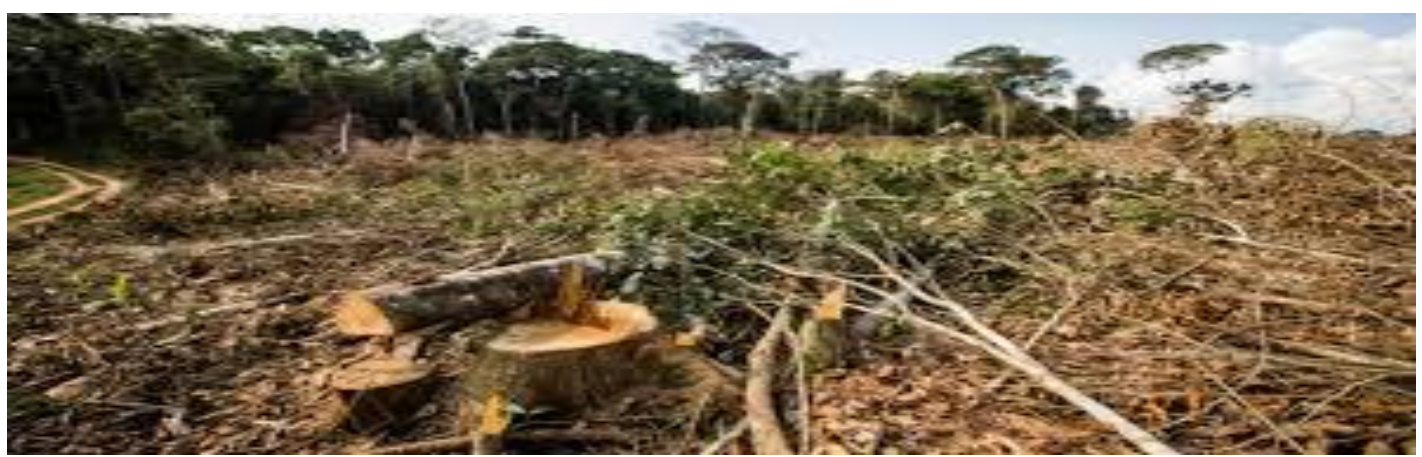

1.1- Pratica de derrubadas nas pequenas propriedades rurais.

As derrubadas na Amazônia são práticas bastante utilizadas nas atividades agrícolas pelos agricultores, essa dinâmica se dá por não ter opções tecnológicas socialmente adaptadas às condições socioeconômicas dos produtores rurais. Essa tecnologia simples e barata que procura abreviar o tempo de recuperação das capoeiras, que serão reaproveitadas para o desenvolvimento de pastagens da criação de pequenas criações de bovinas. A derrubada é um processo de degradação da vegetação nativa de uma região e pode provocar um processo de desertificação. Pois além de devastar as florestas e os recursos naturais, compromete o equilíbrio do planeta em seus diversos elementos, incluindo os ecossistemas, afetando gravemente também a economia e a sociedade. Atualmente a Amazônia Brasileira é a área que mais sofre com o desmatamento. Segundo o Instituto Nacional de Pesquisas Espaciais (Inpe) no mês de junho de 2020, com essa dinâmica ancestral as plantas, os animais e microrganismos ficam debilitadas e eventualmente algumas podem se extinguir. A derrubadas reduz os serviços hidrológicos providenciados pelas árvores, que são fundamentais. É uma prática agressiva e que leva a grandes prejuízos para o meio ambiente. Ao mesmo tempo em que existe há milênios, nunca foi tão importante focar em ações que reduzam a devastação de florestas ao redor do mundo. Além disso, os impactos ambientais trazidos pela derrubada podem levar a graves consequências para a espécie humana.

\section{Revista ALTERJOR}

Grupo de Estudos Alterjor: Jornalismo Popular e Alternativo (ECA-USP)

Ano 12 - Volume 01 - Edição 25 - Janeiro-Junho de 2022 Av. Professor Lúcio Martins Rodrigues, 443, Cidade Universitária, São Paulo, CEP: 05508-020 


\subsubsection{Porque o pequeno produtor rural ainda usa as queimadas na agricultura?}

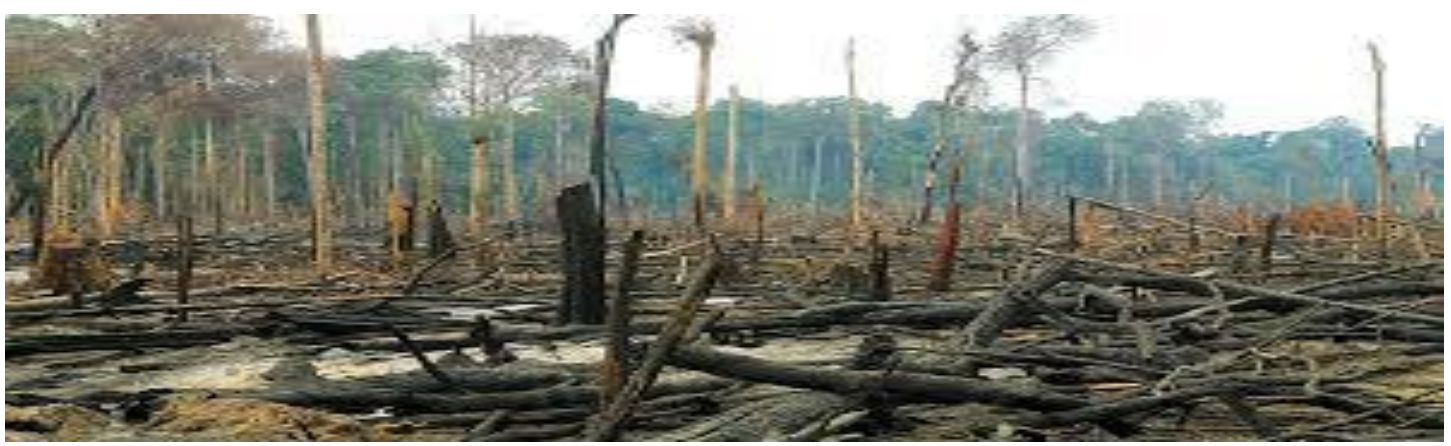

A perpetuação das queimadas, neste cenário, imporá perdas sociais e ambientais de grande monta, dada a elevação do risco de incêndios. A mitigação das consequências requer políticas públicas, as quais, de fato, têm se mostrado eficazes na contenção do desmatamento regional (ASSUNÇÃO et al., 2012). O mesmo, contudo, não pode ser dito quanto às ocorrências de fogo. As queimadas tornam-se um negócio vantajoso para o agronegócio, haja vista que o produtor utiliza a "economia do fogo", que na Amazônia compreende a agropecuária e atividades relacionadas, possui três fundamentos, os quais operam como causas de fundo para a perpetuação das queimadas e, consequentemente, para a manutenção de um nível relevante de risco de incêndio. A maioria dos municípios presentes na lista elaborada pelo Ipam está localizada no chamado arco do desmatamento - que é resultado de um processo histórico de ocupação da Amazônia, entre o fim da década de 1950 e início dos anos 1960.

O primeiro é a alta eficácia do fogo para remover os resíduos da conversão da cobertura da terra, a qual vem acompanhada de um considerável poder fertilizante das cinzas (COCHRANE, 2010, p.391). Esta alta eficácia se traduz em alto retorno econômico, medido como despesa evitada em preparo da terra, tomando-se como base de comparação o preparo manual ou mecanizado da terra. O segundo fundamento é a baixa probabilidade de incêndios em um ambiente ainda dominado pela floresta tropical úmida e com altas taxas de precipitação (VASCONCELOS et al., 2013, Quadro 9). O que implica que a flamabilidade da paisagem na Amazônia, ainda que esteja aumentando (BARLOW et al., 2016), é, em média, relativamente baixa. De fato, o 


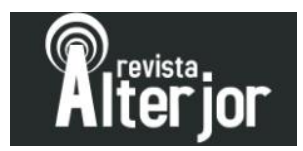

bioma Amazônia apresentou um nível médio de risco de fogo inferior ao nacional em 2015 e 2016, conforme revelam os focos de calor detectados pelo Instituto Nacional de Pesquisas Espaciais (INPE, 2016).

O terceiro fator é o baixo grau de aglomeração da população em geral (e, portanto, de mão de obra e consumidores), e também a baixa densidade infraestrutura (vias de transporte, especialmente), características à Amazônia rural, especialmente em áreas de fronteira. O que dá origem a uma baixa "densidade econômica" medida em riqueza acumulada por hectare tanto sob forma "líquida" como "sólida". I.e., respectivamente, dinheiro armazenado em conta corrente e bens tangíveis (e, pois, passíveis de serem danificados pelo fogo), tais como instalações, cercas, plantios agrícolas, pastagens, etc. A dispersão espacial da riqueza sólida faz com que os impactos dos incêndios pareçam eventos isolados e a escassez de riqueza líquida impede o investimento em práticas que prescindem do fogo (NEPSTAD et al., 1999, 2001).

O grande problema, a nível das pequenas propriedades rurais que envolvem os produtores é que esse sistema ainda usa técnicas milenar que causam impactos ambientais, mas permanecem enraizado na sociedade Contemporânea. Quando o tamanho dos lotes é muito pequeno, dá-se o esgotamento das áreas de florestas densas e, consequentemente, as capoeiras que já foram derrubadas pelo menos por 4 a 5 vezes começam a apresentar problemas de queda de produtividade das culturas. A grande solução para as queimadas seria a interrupção dessa prática pela população, mas sabemos que isso é impossível, uma vez que tal ação é histórica e acompanha os seres humanos desde seus primórdios. A grande solução para as queimadas seria a interrupção dessa prática pela população, mas sabemos que isso é impossível, uma vez que tal ação é histórica e acompanha os seres humanos desde seus primórdios.

Considerando o grau de descapitalização e o fato dos produtores não terem acesso a outras alternativas de preparo do solo a utilização das queimadas se justifica por ser o processo menos oneroso de preparo do solo comparando-se com outros métodos como o de retirada da biomassa constituída de troncos e gralharias. É bom 


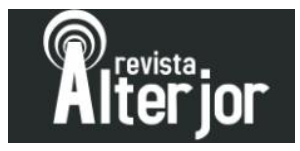

dizer que as queimadas promovem uma fertilização gratuita, em termos de diversos nutrientes, principalmente o potássio, além de auxiliar no controle de ervas daninhas e de pragas. No caso da queimada da capoeira, outra vantagem é a facilidade e a rapidez na remoção da gralharia. Em contrapartida, aumentam bastante as despesas com capinas, limpeza dos restos da vegetação indesejável e combate a pragas, no curso do processo de exploração do solo. Deve ressaltar, ainda, os fatores culturais associados ao uso do solo e o fato de a madeira naquelas condições ser um bem livre e com baixo ou mesmo nenhum valor comercial. Assim, como grande parte das queimadas é oriunda de ações humanas, as soluções para esse problema também passam pela conscientização e mudança de hábitos da sociedade.

\section{2 - As Consequencias das queimadas para a saúde da população}

O processo da prática das queimadas na região Norte teve iniciou na década de 1960, com a ocupação da Amazônia resultado de uma ação histórica, com o desenvolvimento das atividades agrícolas e pecuárias aumentaram as queimadas de forma desordenadas. São provocadas após a derrubada de árvores, geralmente de forma ilegal, a fim de preparar o terreno para agricultura, pastagem ou especulação de terras. As queimadas geralmente atingem seu pico em agosto e setembro. Com o número de queimadas aumentando, a_NASA, agência do governo dos Estados Unidos, divulgou imagens de um satélite mostrando o aumento dos incêndios na floresta.

A repercussão foi aumentando pelo mundo, manifestações começaram a ser realizadas fora do país e o apelo de populares, celebridades mundiais e governantes aumentou a pressão em cima do governo por uma solução para conter as queimadas. Nas redes sociais, a hashtag \#PrayForAmazonia (Ore pela Amazônia) foi uma das mais citadas em todo o mundo durante uma semana. Percebe-se que o aumento de fumaças gerada pelas queimadas vem interferindo na saúde da população, causando graves problemas respiratórios.

Revista ALTERJOR

Grupo de Estudos Alterjor: Jornalismo Popular e Alternativo (ECA-USP)

Ano 12 - Volume 01 - Edição 25 - Janeiro-Junho de 2022 Av. Professor Lúcio Martins Rodrigues, 443, Cidade Universitária, São Paulo, CEP: 05508-020 


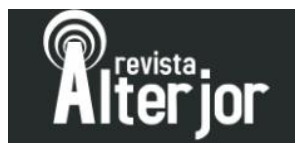

Diante desse cenário é importante ressaltar que as queimadas associadas ao desmatamento desenfreado estão intoxicando o ar que milhões de pessoas respiram e afetando a saúde na Amazônia brasileira, dizem o IPAM (Instituto de Pesquisa Ambiental da Amazônia), o IEPS (Instituto de Estudos para Políticas de Saúde) e a Human Rights Watch em relatório publicado hoje. As queimadas e o desmatamento na Amazônia aumentaram dramaticamente durante 2019 - primeiro ano de governo do presidente Jair Bolsonaro - e 2020 já está se revelando pior, concluíram as organizações. Segundo relatório "O Ar é Insuportável: Os impactos das queimadas associadas ao desmatamento da Amazônia brasileira na saúde" utiliza dados oficiais de saúde e meio ambiente para estimar que 2.195 internações hospitalares por doenças respiratórias em 2019 são atribuíveis às queimadas. Quase 500 internações envolveram crianças com menos de um ano de idade, e mais de mil foram de pessoas com mais de 60 anos. Essas internações representam apenas uma fração do impacto total das queimadas na saúde, considerando que milhões de pessoas foram expostas em 2019 a níveis nocivos de poluição do ar decorrentes das queimadas associadas ao desmatamento da Amazônia. A fumaça é rica em material particulado fino, um poluente ligado a doenças respiratórias e cardiovasculares, bem como morte prematura. Crianças, pessoas idosas, gestantes e pessoas com doenças pulmonares ou cardíacas preexistentes são especialmente vulneráveis.

Esse aumento de pessoas internadas nos hospitais com graves problemas respiratórios é em virtude das queimadas, com isso cresce as internações de pessoas com quadros respiratórios agudos graves (SRAG) entre os meses de agosto e outubro, época da maioria dos focos de incêndio no bioma, que trazem consigo os efeitos da fumaça das queimadas na saúde respiratória da população. Segundo informações da Secretária Municipal de Saúde de Altamira Pará dia 23 de outubro de 2020, cerca de $63 \%$ das internações desse tipo na cidade de Altamira Pará, foram casos confirmados de Covid e $23 \%$ não tiveram a causa definida. Entre as pessoas hospitalizadas com confirmação de Covid, $30 \%$ faleceram. Nesse sentido as queimadas e pandemia formaram uma grave combinação justamente no Pará e na região de Altamira. De acordo com relato da moradora Ana Paula Cardoso moradora do Município de Altamira

\section{Revista ALTERJOR}

Grupo de Estudos Alterjor: Jornalismo Popular e Alternativo (ECA-USP)

Ano 12 - Volume 01 - Edição 25 - Janeiro-Junho de 2022

Av. Professor Lúcio Martins Rodrigues, 443, Cidade Universitária, São Paulo, CEP: 05508-020 


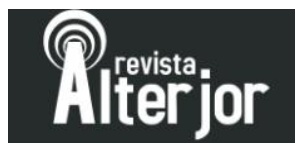

Pará onde vive - agosto, o mês com mais internações no estado, foi o segundo com mais focos de incêndio no ano. As queimadas, que começaram a aumentar em julho, quando ela adoeceu, só foram diminuíram em dezembro.

\section{1- Poluição do ar e riscos de neoplasias}

Um aspecto muito importante relacionado às emissões de queimadas é seu efeito a longo prazo, com aumento do risco de neoplasias pela presença de substâncias cancerígenas ou suspeitas de ação cancerígena, como as dioxinas, furanos e hidrocarbonetos policíclicos aromáticos (HPAs). Esses compostos podem estar presentes tanto no material particulado quanto na fase gasosa. $\mathrm{O}$ material particulado resultante da combustão incompleta - como a que ocorre nas queimadas - é reconhecidamente cancerígeno em animais, com possível ação cancerígena também no Homem.

As de benzo-para-dioxinas policloradas (PCDDs) e os dibenzofuranos policlorados (PCDFs), comumente chamados de dioxinas e furanos, são duas classes de compostos aromáticos tricíclicos, de função éter, com estrutura quase planar, e que possuem propriedades físicas e químicas semelhantes. Os átomos de cloro se ligam aos anéis benzênicos, possibilitando a formação de um grande número de congêneres: 75 para as dioxinas e 135 para os furanos, totalizando 210 compostos. A combustão tem sido considerada a principal fonte de emissão de dioxinas e furanos para a atmosfera. Das 210 dioxinas e furanos existentes, 17 compostos com substituições na posição 2,3,7 e 8 destacam-se sob o ponto de vista toxicológico. A toxicidade aguda mais elevada é para a 2,3,7,8-tetra-clorodibenzo-p-dioxina (2,3,7,8-TCDD), ultrapassada somente por algumas toxinas de origem natural (Grossi, 1993, apud Assunção \& Pesguero, 1999).

Uma reavaliação dos efeitos das dioxinas e furanos feita pela USEPA em 1994 (USEPA, 1994) concluiu que a TCDDs exerce seu efeito carcinogênico, primariamente mediante sua efetividade como agente promotor de estimulação da replicação de células numa maneira reversível. Esse mecanismo é mediado presumivelmente pelo receptor. Ah (receptor de hidrocarboneto aromático) e por mecanismos transducionais associados.

Revista ALTERJOR

Grupo de Estudos Alterjor: Jornalismo Popular e Alternativo (ECA-USP)

Ano 12 - Volume 01 - Edição 25 - Janeiro-Junho de 2022

Av. Professor Lúcio Martins Rodrigues, 443, Cidade Universitária, São Paulo, CEP: 05508-020 


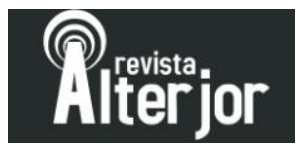

Portanto, as TCDDs não são carcinógenos completos e não deveriam ser designados como tal. A 2,3,7,8-TCDD, sob certas condições de exposição, é capaz de aumentar a incidência de câncer em humanos. As TCDDs estão classificadas pela USEPA no grupo B1 (provável carcinogênico humano com base em informação limitada de estudos em humanos assim como em animais) (USEPA/SAB 1995). Em 1997 a Organização Mundial da Saúde alterou a classificação da 2,3,7,8-TCDD de provável cancerígeno em humanos (grupo 2A) para cancerígeno ao ser humano (grupo 1) (WHO/IARC, 2001).

Segundo Pitts (1987 apud. Vasconcellos, 1996) os HPAs são emitidos principalmente na fase gasosa, embora uma porção significante - os HPAs mais pesados - esteja associada às partículas finas carbonadas. Os HPAs podem ser convertidos nos seus derivados nitratos quando expostos a agentes, entre eles, particularmente ativos, $\mathrm{NO}, \mathrm{HNO}_{3}, \mathrm{~N}_{2} \mathrm{O}_{5}$ e radicais $\mathrm{NO}_{3}$. Os dois primeiros, que convertem os HPAs adsorvidos em partículas, estão presentes nas queimadas ou são resultantes de reações dessas emissões na atmosfera.

\section{2- Quais os impactos da poluição do ar à saúde daqueles já prejudicados por} alguma doença, pela idade ou por condições socioeconômicas?

Os vários fatores que levaram aos os impactos da poluição do ar à saúde daqueles já prejudicados por alguma doença, pela idade ou por condições socioeconômicas? Esta parece ser uma questão a ser respondida pelas pesquisas, para que seja garantido o direito universal ao ar limpo. De acordo com a pesquisa realizada por Radojevic \& Hassan (1999), registrou concentrações horárias de ozônio num período de névoa causada por queimada que variaram de 5,1 a $99,9 \mu \mathrm{g} / \mathrm{m}^{3}$, com média de $63,3 \mu \mathrm{g} / \mathrm{m}^{3}$ no período de $1^{\circ}$ de fevereiro a 30 de abril de 1998 . Esses dados levaram os autores a afirmar que, apesar do ozônio ser produzido em incêndios florestais em diferentes quantidades, suas concentrações durante esses episódios aparentemente não apresentam riscos à saúde pública (Radojevic \& Hassan, 1999). A circulação da fumaça tem efeitos negativos para a saúde humana.

Revista ALTERJOR

Grupo de Estudos Alterjor: Jornalismo Popular e Alternativo (ECA-USP)

Ano 12 - Volume 01 - Edição 25 - Janeiro-Junho de 2022

Av. Professor Lúcio Martins Rodrigues, 443, Cidade Universitária, São Paulo, CEP: 05508-020 


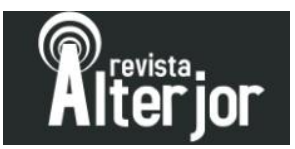

Os impactos decorrentes das fumaças emitidas pelas queimadas ainda não foram bem avaliados, mas afetam um número significativo de pessoas, sobretudo nos países em desenvolvimento, onde a queimada constitui uma prática agrícola bastante difundida. Além disso, incêndios são constantes durante os meses de inverno, quando a reduzida precipitação leva à perda de umidade da massa vegetal, propiciando a ocorrência de queimadas intencionais e involuntárias que fogem ao controle. Esse conhecimento é importante para a definição de políticas de controle e de estabelecimento de padrões de qualidade do ar específicos para o caso das queimadas. $\mathrm{O}$ monitoramento e o estabelecimento de padrões de qualidade do ar, muito usados para avaliar e controlar a qualidade do ar urbano, mostram-se inadequados para avaliar a poluição causada por queimadas e não levam em consideração a exposição a concentrações extremamente elevadas a curto prazo.

Como as situações são muito dinâmicas, os estudos precisam avaliar os riscos de novos agentes e de novas situações. A avaliação das rápidas e constantes mudanças na atmosfera constitui um desafio para futuras pesquisas. Outro aspecto importante é a maior inclusão do mundo não-desenvolvido e em desenvolvimento nesses estudos. Finalmente, estudos sobre outros efeitos da poluição do ar para a saúde, não só a saúde respiratória, são raros e preliminares. Muitos de seus resultados são evidências nãoconclusivas. No futuro, há urgência na realização de estudos mais amplos, envolvendo ainda mais profissionais, de diferentes áreas. "A questão das queimadas acontece todo ano. Com isso a um aumento, principalmente de crianças, mas de adultos também, que procuram o pronto atendimento no hospital com problemas respiratórios, ou agravamento do quadro respiratório que já têm. Fica agudizado, começam a ter crises", relata F da S. P., coordenador da Atenção Básica e enfermeiro plantonista do Hospital Regional de Altamira. Ele conta que a sobreposição das queimadas com a pandemia em 2020 dificultou o atendimento no hospital, com grande aumento de pacientes com sintomas respiratórios em dúvida se estavam com Covid ou sofrendo os efeitos da fumaça. "Tudo que envolve alguma coisa relacionada ao sistema respiratório a gente já tem que desconfiar de Covid".

Revista ALTERJOR

Grupo de Estudos Alterjor: Jornalismo Popular e Alternativo (ECA-USP)

Ano 12 - Volume 01 - Edição 25 - Janeiro-Junho de 2022

Av. Professor Lúcio Martins Rodrigues, 443, Cidade Universitária, São Paulo, CEP: 05508-020 


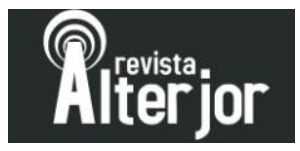

\section{3 - As consequências das queimadas para o solo e sobsolo.}

Analisando a metodologia do século XX utilizada na agricultura e pecuária constata se que a mesma dinâmica se aplica no Século XXI, o sistema ancestral perpetua no contexto atual. Mesmo essa dinâmica estando nos debates e discussões no sentido de evitar a prática das queimadas ainda prevalecem. Nesse sentido percebe-se que a passagem do fogo sobre o solo acarreta danos químicos, físicos e biológicos apesar de alguns agricultores utilizarem queimadas por acreditarem na melhoraria da fertilidade do solo, porém essa ação não traz benefício a longo prazo.

Os impactos nos atributos químicos do solo causado pela queimada do material seco sobre o solo influenciam a fertilidade do solo pela presença das cinzas, que são compostas dos nutrientes mineralizados da parte vegetal queimada. As cinzas, por serem ricas em nutrientes como cálcio, fósforo, magnésio, nitrogênio, entre outros, dão a impressão de aumentar a fertilidade do solo. Entretanto, esse aumento é por pouco tempo. Com a chegada das chuvas, as cinzas são lixiviadas, ocorrendo diminuição dos nutrientes nas camadas superiores do solo. Além disso, com lixiviação dos nutrientes, principalmente compostos nitrogenados e o potássio, a qualidade da água superficial e subterrânea é afetada.

Com a retirada do material vegetal, seja palhada ou matéria verde, o solo fica desprotegido, sofrendo mais com a ação do sol e chuva. Com essa ação o solo passa pelo processo de transformação sofrendo impactos nos atributos físicos do solo. Em solos desprotegidos, a ocorrência de chuvas fortes ou com alta frequência, favorece o processo de erosão, que leva a camada superficial do solo e seus nutrientes com a água das chuvas. Com o calor ocasionado pelo fogo, ocorre perda de água pela evaporação na camada superficial do solo. Desse modo, pode ocorrer uma camada compactada. Às queimadas provocam mudanças nas propriedades físicas do solo como macro poros, tamanho de agregados e taxa de infiltração, são afetados com o calor do fogo. $\mathrm{O}$ aumento da densidade dificulta a infiltração da água e penetração das raízes, afetando a umidade e a vida dos microrganismos do solo. Após a queimada, ocorrem ainda 


\section{ARtejior}

mudanças nestas propriedades, podendo levar ao aumento da densidade do solo na camada superficial.

Com as queimadas são atingidos os microrganismos, com isso as novas culturas inseridas no solo ficam vulneráveis, haja vista que os microrganismos são importantes na decomposição da matéria orgânica e ciclagem de nutrientes, além de aumentarem a porosidade, aeração, infiltração e drenagem do solo, devido à movimentação desses organismos no perfil do solo. E, como consequências das queimadas no solo, a macrofauna e microfauna do solo são reduzidas, principalmente nas camadas superficiais, causando os impactos nos atributos biológicos do solo. Com a redução do ar e água presentes no solo, os organismos do solo são diretamente afetados.

De acordo com Rodney de Arruda Mauro, biólogo, doutor em ecologia tropical e pesquisador da Embrapa Gado de Corte. Ele ressaltou os prejuízos que o fogo traz para o solo e deu dicas para o produtor evitar as queimadas dentro de suas fazendas. "O problema é muito grande. Como existe a cultura do fogo, nós, pesquisadores, orientamos para que não se realize esse tipo de atividade nas propriedades porque muito mais prejudica o solo e também traz vários outros problemas relacionados com queimada", disse o pesquisador, listando entre as consequências a morte da fauna e da flora e problemas de saúde para o próprio ser humano que inala a fuligem.

Diante desse cenário ao contrário do que pensa uma parte dos produtores, a impressão de que a queimada renova os nutrientes do solo é equivocada, destacou Rodney. "Você chega a perder 90\% dos nutrientes do solo", quantificou. A impressão de que a qualidade da solo melhora se dá porque em um primeiro momento a cinza pode melhorar de modo efêmero o desempenho das plantas, mas logo este efeito se perde porque a cinza é levada nas primeiras chuvas, enquanto os demais nutrientes foram levados pelo ar junto à fuligem. Rodney ainda comentou alguns dos modos de os produtores evitarem e estarem preparados para eventuais incêndios acidentais, confirmando que até $60 \%$ deles começam na beira das estradas. As queimadas causam consequências no Meio Ambiente irreparável. Elas são consideradas uma ação antrópica, ou seja, são ações humanas que provocam grande impacto no meio ambiente.

Revista ALTERJOR

Grupo de Estudos Alterjor: Jornalismo Popular e Alternativo (ECA-USP)

Ano 12 - Volume 01 - Edição 25 - Janeiro-Junho de 2022

Av. Professor Lúcio Martins Rodrigues, 443, Cidade Universitária, São Paulo, CEP: 05508-020 


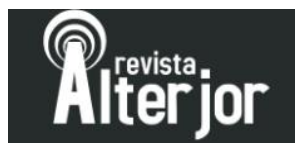

Neste caso, estamos falando de impactos negativos, já que causam o desequilíbrio ecológico.

\section{1 as queimadas provocam perda de nutrientes.}

Com a realização da pesquisa no Assentamento constatamos que as queimadas trazem sérios prejuízos ao solo e à agricultura. Embora exigida liberação para execução das queimadas descontroladas, com insubordinação as queimadas são constantes. As queimadas causam danos à fertilidade do solo - empobrecendo-o em nutrientes, ao meio ambiente, à saúde pública, aos animais e à vegetação. $\mathrm{O}$ que se percebesse que são práticas enraizadas mesmo existindo Leis Ambientais que tentam coibir esse tipo de ações o sistema ainda é muito frígio, falta atuação de Políticas Públicas. Com os problemas que as queimadas causam na natureza podemos cita a perda de nutrientes do solo é elevada, sem falar na emissão de fumaças acarretando os problemas respiratórios.

A pesquisa iniciou no dia $1^{\circ}$ de maio de 2020 , foram coletadas amostra de sete lotes do assentamento Bom Jardim I, com o objetivo de observar a quantidade de nutrientes existentes no solo antes da queimada da vegetação do assentamento, a coleta das amostras foi realizada através de entrevistas com os assentados e do método de extração e irradiação, com 10-20 cm, 20-40 e 40-60 cm, transecto, 40 pontos distando $10 \mathrm{~m}$ entre eles, perfazendo no total $400 \mathrm{~m}$, em sete lotes do assentamento. $\mathrm{O}$ delineamento estatístico utilizado foi de blocos casualidades com parcelas subdivididas. A (posição da amostragem) em dois etapas, ou seja, área nativa e na área queimada, (Bom Jardim I), veja a tabela 1.

Tabela 1. Pesquisa realizada antes da derrubada e queimada da vegetação.

\begin{tabular}{|l|l|l|l|l|l|l|l|}
\hline Nutrientes & Lote 1 & Lote 2 & Lote 3 & Lote 4 & Lote 5 & Lote 6 & Lote 7 \\
\hline Nitrogênio (N) & 964 & 862 & 932 & 930 & 931 & 935 & 937 \\
\hline Fósforo (P) & 21 & 20 & 19 & 20 & 21 & 19 & 20 \\
\hline
\end{tabular}

\section{Revista ALTERJOR}

Grupo de Estudos Alterjor: Jornalismo Popular e Alternativo (ECA-USP)

Ano 12 - Volume 01 - Edição 25 - Janeiro-Junho de 2022 


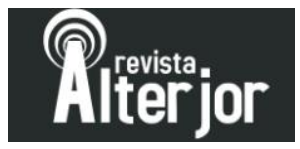

\begin{tabular}{|l|l|l|l|l|l|l|l|}
\hline Potássio (k) & 86 & 90 & 91 & 91 & 87 & 86 & 90 \\
\hline Microrganismo & 30 & 45 & 49 & 38 & 36 & 39 & 42 \\
\hline
\end{tabular}

A $2^{\mathrm{a}}$ coleta de amostra fora coletada após a derrubada e queimada da vegetação, a mesma dinâmica foi realizada após a queimada. Nesse sentido a quantidade de nutrientes que o solo perdeu com a queimada da vegetação é grande, veja as quantidades. As perdas com fósforo são maiores, pois as queimadas, conforme o ambiente, podem ocasionar perdas de 4 a $11 \mathrm{~kg} / \mathrm{ha} \mathrm{P}$. Se o solo, em média, contém 2 $\mathrm{mg} / \mathrm{dm}^{3} \mathrm{P}$ ou $4 \mathrm{~kg} / \mathrm{ha}\left(\mathrm{mg} / \mathrm{dm}^{3} \times 2=\mathrm{kg} / \mathrm{ha}\right)$, numa única queimada seria eliminado todo o fósforo disponível existente no solo, as perdas podem atingir $4 \mathrm{~kg} / \mathrm{ha}$ de $\mathrm{P}$, as perdas de potássio chegam a $42 \mathrm{~kg} / \mathrm{ha}$ e $52 \%$ de nutrientes. Com as altas temperaturas das queimadas, há volatilização de nutrientes. A cinza formada da queima atinge até 400 $\mathrm{kg} / \mathrm{ha}$ e há um aumento na concentração de $\mathrm{K}, \mathrm{Ca}$ e $\mathrm{Mg}$ na camada superficial do solo, mas que se perde com o passar do tempo, levada pelos ventos e pelas chuvas. Veja a tabela 2 .

Tabela 2. Pesquisa realizada depois a queimada da vegetação ocasionou a perda de nutrientes.

\begin{tabular}{|l|l|l|l|l|l|l|l|}
\hline Nutrientes & Lote 1 & Lote 2 & Lote 3 & Lote 4 & Lote 5 & Lote 6 & Lote 7 \\
\hline Nitrogênio (N) & 620 & 621 & 630 & 632 & 631 & 632 & 620 \\
\hline Fósforo (P) & 4 & 5 & 4 & 4 & 5 & 6 & 7 \\
\hline Potássio (k) & 40 & 41 & 43 & 42 & 44 & 40 & 45 \\
\hline Microrganismo & 10 & 15 & 11 & 13 & 12 & 16 & 17 \\
\hline
\end{tabular}

As queimadas trazem diversas desvantagens quando utilizadas. A cobertura do solo é responsável para evitar as perdas de nutrientes e matéria orgânica pela ação das águas das chuvas e pela erosão eólica. Além disto, a cobertura vegetal é responsável

\section{Revista ALTERJOR}

Grupo de Estudos Alterjor: Jornalismo Popular e Alternativo (ECA-USP)

Ano 12 - Volume 01 - Edição 25 - Janeiro-Junho de 2022 


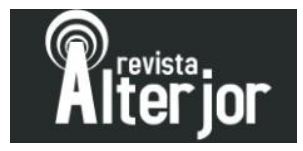

pelo aumento do teor de matéria orgânica do solo, formada pela decomposição de galhos e folhas que caem no solo.

Todos conhecem o papel primordial da matéria orgânica do solo na melhoria da fertilidade do solo e no aumento da produtividade das culturas. É fonte de nitrogênio (N) para o solo. Nas recomendações de adubação. Quanto maior o teor de matéria orgânica do solo menor serão as quantidades de adubos nitrogenados recomendados. A matéria orgânica melhora a estrutura física do solo agregando as partículas e diminuindo os problemas de compactação nos solos argilosos ou a desagregação nos solos arenosos. A matéria orgânica do solo funciona como um verdadeiro reservatório de nutrientes e água, liberando-os para a planta. Com a queimada há uma destruição da matéria orgânica e, como consequência, uma pobreza de nutrientes.

Quem perde com isto é o produtor que deverá utilizar quantidades maiores de fertilizantes para compensar, e isto se traduz em aumento do custo da lavoura. Outro prejuízo das queimadas é a emissão de gases de efeito estufa como o $\mathrm{CO} 2, \mathrm{NO} 2$ e enxofre (S), causando um desequilíbrio no meio ambiente. Alguns apontam que as queimadas são responsáveis por $70 \%$ das emissões de $\mathrm{CO} 2$ para o ar.

Sampaio et al. (2003) estudaram o "balanço de nutrientes e da fitomassa em um solo argissolo amarelo, sob floresta tropical, após a queima e cultivo com arroz". Após a derrubada e queima da mata, instalaram um experimento para comparar áreas queimadas sem cultivo e áreas queimadas com arroz cultivado. Como referência foi utilizada uma área de mata. A realização da queimada consumiu 38,5\% da biomassa inicial e originou 6,6 t/ha de cinzas com bastante quantidades de $\mathrm{Ca}, \mathrm{Mg}$ e $\mathrm{K}$. Houve perdas de N, P, K, Ca, Mg e S, tanto pela ação do fogo como pela ação do vento sobre as cinzas e remoção pela cultura. Concluíram que a queimada sem cultivo proporcionou maiores perdas de nutrientes em relação a queimada com arroz cultivado, pela importância da cobertura do solo. Quanto ao efeito residual das cinzas, os valores de P, $\mathrm{K}, \mathrm{Ca}$ e $\mathrm{Mg}$ foram superiores.

Revista ALTERJOR

Grupo de Estudos Alterjor: Jornalismo Popular e Alternativo (ECA-USP)

Ano 12 - Volume 01 - Edição 25 - Janeiro-Junho de 2022 Av. Professor Lúcio Martins Rodrigues, 443, Cidade Universitária, São Paulo, CEP: 05508-020 


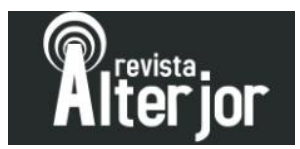

\section{Resultado e discussão}

A derrubada e queimada é uma prática primitiva usada com frequência na Região Norte pelos pequenos e grandes produtores, destinada a limpeza de área de pastagem e terreno para o desenvolvimento de culturas diversificadas, porém o desenvolvimento de ações com o uso continuo do fogo provoca desequilíbrio ecológico e o enfraquecimento do solo, causando perda de nutrientes. Com o propósito de comprovar a perda de nutrientes em virtude das queimadas no assentamento, uma pesquisa foi realizada. O resultado final das amostras retiradas de 7 lotes diferentes, foram analisadas no laboratório antes e após da derruba e da queimada da vegetação nativa, a coleta das amostras iniciou no mês de maio antes da queimada, finalizando no mês de dezembro, após a queimada da vegetação. Os dados da pesquisa são apresentados na tabela 3, com as informações dos nutrientes da vegetação nativa antes da queimada e a $2^{\text {a }}$ coleta da amostra após a queimada da vegetação, a qual consta a perda de nutrientes como: Nitrogênio $(\mathrm{N})$, Fosforo $(\mathrm{P})$, Potássio (k) e Microrganismo. Pelos resultados encontrados pode-se afirmar que houve alterações significativas com relação a perda de nutrientes N, P, K e Microrganismo.

Nas queimadas, a maior perda é com o nitrogênio que vai para a atmosfera em forma de fumaça. Outros nutrientes são liberados juntos. Pivello et al. (1992 citados pela Embrapa) avaliaram a quantidade de nutrientes, ou seja, N, P, K, Ca, Mg e S, que foram transferidos para a atmosfera durante as queimadas experimentais em campocerrado de Emas, em Pirassununga, SP. O resultado encontrado por Oliveira et al (2005), em trabalho semelhante indica uma redução de nutrientes com as queimadas. Comparam a quantidade de nutrientes na vegetação herbáceo-arbustiva e na cinza resultante da queimada. As médias de perdas de nutrientes foram as seguintes: $20,6 \mathrm{~kg}$ $\mathrm{N}, 1,6 \mathrm{~kg} \mathrm{P}, 7,1 \mathrm{~kg} \mathrm{~K}, 12,1 \mathrm{~kg} \mathrm{Ca}, 3,0 \mathrm{~kg} \mathrm{Mg}$ e $59 \%$ de S. Verifica-se, portanto, que as perdas de $\mathrm{N}$, P, e K são de de $\mathrm{N}$, depois K e finalmente o P.

Revista ALTERJOR

Grupo de Estudos Alterjor: Jornalismo Popular e Alternativo (ECA-USP)

Ano 12 - Volume 01 - Edição 25 - Janeiro-Junho de 2022 Av. Professor Lúcio Martins Rodrigues, 443, Cidade Universitária, São Paulo, CEP: 05508-020 


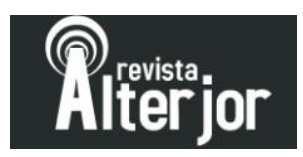

\begin{tabular}{|l|l|l|l|l|l|l|l|}
\hline Nutrientes & Lote 1 & Lote 2 & Lote 3 & Lote 4 & Lote 5 & Lote & $\begin{array}{l}\text { Lote } \\
7\end{array}$ \\
\hline $\begin{array}{l}\text { Nitrogênio: Antes d/queimada. } \\
\text { Após queimada da vegetação. }\end{array}$ & 964 & 862 & 932 & 930 & 931 & 935 & 937 \\
\hline Fósforo (P): Antes d/queimada. & 21 & 621 & 630 & 632 & 631 & 632 & 620 \\
Após queimada da vegetação. & 04 & 05 & 04 & 04 & 05 & 06 & 07 \\
\hline Potássio (k): Antes d/queimada. & 86 & 90 & 91 & 91 & 87 & 86 & 90 \\
Após queimada da vegetação. & 40 & 41 & 43 & 42 & 44 & 40 & 45 \\
\hline Microrganismo: Antes/d/q & 30 & 45 & 49 & 38 & 36 & 39 & 42 \\
Após queimada da vegetação. & 10 & 15 & 11 & 13 & 12 & 16 & 17 \\
\hline
\end{tabular}

Os resultados da amostragem de solo mostraram uma diminuição dos nutrientes, após as derrubadas e queimadas, esse processo de perca de deu diante da alta temperatura do fogo.

\section{Conclusão}

Através da pesquisa foi possível comprovar que a prática de derrubada e queimada descontrolada provoca a redução de nutrientes como: Nitrogênio $(\mathrm{N})$, Fósforo (P), Potássio (k) e Microrganismo houve o decréscimo dos valores dos nutrientes, nesse sentido o solo torna-se enfraquecido, as produções de culturas diversificadas passam a ter menos qualidade. No entanto a uma impressão dos produtores que o solo a partir da queimada torna-se mais fértil, por falta de informação e conhecimento essa prática perpetua no assentamento. Portanto diante desse resultado é importante que o estado e os órgãos competentes implantem Políticas Públicas mais atuantes com ações consistente e conscientização dos assentados, com relação ao uso correto do solo, devolvendo outras dinâmicas que agridam menos o solo.

\section{Revista ALTERJOR}

Grupo de Estudos Alterjor: Jornalismo Popular e Alternativo (ECA-USP)

Ano 12 - Volume 01 - Edição 25 - Janeiro-Junho de 2022 


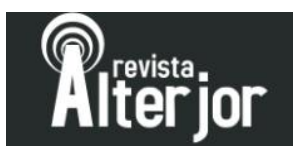

\section{REFERÊNCIAS}

ARAÚJO, T. M. et al A tropical rainforest experiment by biomass burning in the state of Pará, Brazil. Atmospheric Environment 33, 1991-1998, 1999.

ARBEX, M. A.; BÖHM, G. M.; SALDIVA, P.H.N.; CONCEIÇÃO, G.; POPEIII, A.G. \& BRAGA, A. L. F. Assessment of the effects of sugar cane plantation burning on daily counts of inhalation therapy. Journal of the Air \& Waste Management Association 50, p. 1745-1749, Oct 2000.

ARTAXO, P.; FERNANDES, E. T.; MARTINS, J. V.; YAMASOE, M.A.; HOBBS, P.V.; MAENHAUT, W.; LONGO, K. M. \& CASTANHO, A. Large-scale aerosol source apportionment in Amazonia. Journal of Geophysical Research- D: Atmospheres, v. 103, n.24, p. 31837-31847, Dec. 1998.

ASSUNÇÃO, J.V. \& PESQUERO, C.R. Dioxinas e furanos: origens e riscos. Revista de Saúde Pública, v. 33, n. 5, São Paulo, 1999.

AUDY, J.R. Measurement and diagnosis of health. In Shepard, P. \& McKinley, D. (eds.) Environ/mental. essays on the planet as a home. New York, Houghton Mifflin, 1971.

BRUCE, N.; PEREZ-PADILLA, R. \& ALBALAK, R. Indoor air pollution in developing countries: a major environmental and public health challenge. Bulletin of the World Health Organization, v 78, n. 9, p. 1078-1092, 2000.

CETESB (Companhia de Tecnologia de Saneamento Ambiental). Relatório de Qualidade do Ar no Estado de São Paulo-1998. São Paulo, CETESB, 1999.

CHAN, N.Y.; EBI, K.L.; SMITH, F.; WILSON, T.F. \& SMITH, A.E. An integrated assessment framework for climate change and infectious diseases. Environmental Health Perspectives, v. 107, n. 5, May 1999.

COCHRANE, M.A. O significado das queimadas na Amazônia. Ciência Hoje, v. 27, n. 157, SBPC, S. Paulo, jan./fev. 2000.

COMMITTEE OF THE ENVIRONMENTAL and Occupational Health Assembly of the American Thoracic Society. Health effects of outdoor air pollution: state of the art. American Journal of Respiratory and Critical Care Medicine, v. 153, p. 3-50; 477498, 1996.

CONARD, S.G. \& IVANOVA, G. A. Wildfire in Russial boreal forests: potential impacts of fire regime characteristics on emissions and global carbon balance estimates. Environmental Pollution, v. 98, n. 3, p. 305-313, Elsevier, Great Britain, 1997.

DUBOS, R. Man adapting. New Haven, Yale University Press, 1961.

EMATER DISTRITO FEDERAL. Gerência de Agroecologia e Meio Ambiente. EMATER-DF.

Disponível em:<http://www.emater.df.gov.br/sites/200/229/00003951.pdf> Acesso em: 05 de Set. 2012.

Revista ALTERJOR

Grupo de Estudos Alterjor: Jornalismo Popular e Alternativo (ECA-USP)

Ano 12 - Volume 01 - Edição 25 - Janeiro-Junho de 2022

Av. Professor Lúcio Martins Rodrigues, 443, Cidade Universitária, São Paulo, CEP: 05508-020 


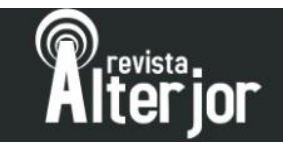

EMBRAPA. Queimadas, suas causas e consequências. Disponível em:<http://www.riosvivos.org.br/Noticia/Queimadas++suas+causas+e+consequencias/1 1159> Acesso em 04 de Ago. 2012.

INDRIUNAS, L. HowStuffWorks - Como funcionam as queimadas. Publicado em 06 de março de 2008 (atualizado em 02 de outubro de 2008). Disponível em:<http://ambiente.hsw.uol.com.br/queimadas1.htm> Acesso em: 04 de Set. 2012.

OLIVEIRA, I. P.; SANTOS, K. J. G.; ARAUJO, A. A.; OLIVEIRA, L. C. Queimadas e suas consequências na Região Centro-Oeste. Revista Eletrônica Faculdade Montes Belos, Goiás, ISSN 1808-8597, v.1, n.2, p. 88 -103, nov. 2005. Disponível em: <http://www.fmb.edu.br/revista/edicoes/vol_1_num_2/queimadas.pdf> Acesso em: 03 de Set. 2012.

SAMPAIO, F. A. R.; FONTES, L. E. F.; JUCKSCH. Balanço de nutrientes e da fitomassa em um Argissolo Amarelo sob floresta tropical amazônica após a queima e cultivo com arroz. Revista Brasileira de Ciências do Solo. V.27. N.6. A.2003.

HOMMA,A. K. O.;TEIXEIRA FILHO,A.R.;MAGALHÃES,E.P.Análise do preço da terra como recurso natural durável: o caso da Amazônia. REconSociolRural, Brasília, 22(2): 103-116, abr./jun. 1991. 